\title{
Aggressive clinical course of large cell neuroendocrine carcinoma of the ampulla of Vater
}

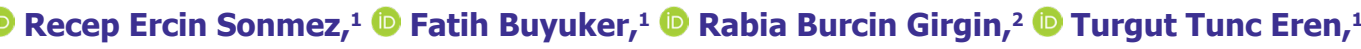 \\ Durhan Bas, ${ }^{1}$ (D) Orhan Alimoglú ${ }^{1}$ \\ ${ }^{1}$ Department of General Surgery, Istanbul Medeniyet University Faculty of Medicine, Istanbul, Turkey \\ ${ }^{2}$ Department of Pathology, Istanbul Medeniyet University Faculty of Medicine, Istanbul, Turkey
}

\begin{abstract}
A 78-year-old male patient with a history of the right hemicolectomy due to the adenocarcinoma was admitted by the complaint of epigastric discomfort. Laboratory data showed an increase in liver biochemistries (aspartate aminotransferase (AST): $159 \mathrm{IU} / \mathrm{L}$, alanine aminotransferase (ALT):235 IU/L, alkaline phosphatase (ALP): $350 \mathrm{IU} / \mathrm{L}$, gamma-glutamyl transferase (GGT): $911 \mathrm{IU} / \mathrm{L}$, total bilirubin: $1.55 \mathrm{mg} / \mathrm{dl}$ and direct bilirubin: $0.82 \mathrm{mg} / \mathrm{dl}$ ). Endoscopic retrograde cholangiopancreatiography (ERCP) administered after the gastrointestinal (GI) upper endoscopy was compatible with the tumoral lesion, and biopsy confirmed 'neuroendocrine carcinoma'. Pylorus-preserving pancreaticoduodenectomy (PPPD) was performed with R0 resection. Pathologic evaluation revealed a $1,5 \mathrm{~cm}$ tumor of large cell neuroendocrine carcinoma (LCNEC). Five months later, biopsy of suspicious lesions in the liver was documented as 'high-grade neuroendocrine carcinoma metastasis'. He was referred to the oncology for chemotherapy, but, unfortunately, he expired three months later. Large cell neuroendocrine carcinoma (LCNECS) of the ampulla of Vater might have an aggressive clinical course despite radical resections involving lymph node dissections. Small tumor size and lymph node negativity are not reliable factors for this tumor type.
\end{abstract}

Keywords: Ampulla of Vater; large cell type; neuroendocrine tumor.

Cite this article as: Sonmez RE, Buyuker F, Girgin RB, Eren TT, Bas G, Alimoglu O. Aggressive clinical course of large cell neuroendocrine carcinoma of the ampulla of Vater. North Clin Istanb 2021;8(1):97-100.

Nong

Teuroendocrine tumors (NETs) of the ampulla of 1 Vater are very rare neoplasms of digestive tract with the prevalence of less than $5 \%$ of all duodenal malignancies and less than $2 \%$ of gastrointestinal neuroendocrine tumors [1]. In 2010, (WHO) World Health Organization diagnostic criteria classified NETs as NET G1 (Low grade), G2 (Intermediate grade), and G3 [High grade or neuroendocrine carcinoma (NEC)], and mixed adenoneuroendocrine carcinoma [MANEC]) [2].

Neuroendocrine tumors are yellowish-grayish in color with a nodular or polypoid appearance. G1 and G2 NETs are mostly located in the mucosa or submucosa, whereas G3 NETs (NECs) appear as ulcerated masses invading deeper layers of the GI system. NECs are histologically classified as LCNEC (Large cell neuroendocrine carcinoma) and SCNEC (Small cell neuroendocrine carcinoma). Large-cell neuroendocrine carcinomas are composed of medium-large cell-sized tumor cells, having a nuclear to cytoplasmic ratio lower than that of small-cell neuroendocrine carcinomas [3].

As a general review, NECs having tumor size greater than $2 \mathrm{~cm}$, muscularis propria invasion with/or involvement of lymph nodes have a tendency to make distant metastasis. Surgery holds the mainstay in the treatment for these tumors. Also, some authors mention the reliability of more conservative treatment (endoscopic in- 
terventions) for the management of early-stage NECs of the ampulla of the Vater.

There are only few studies discussing the clinical course of LCNECs in the literature [4]. This case study is about a 78-year-old male patient diagnosed with LCNEC of the ampulla of Vater.

\section{CASE REPORT}

A 78-year-old man was presented with jaundice and discomfort in the epigastric region of abdomen. He had a history of right-hemicolectomy three years ago due to colonic adenocarcinoma and completed his adjuvant chemotherapy with six cures of capecitabine plus oxaliplatin. On his admission, laboratory data showed an increase in his liver biochemistries [aspartate aminotransferase (AST): $159 \mathrm{IU} / \mathrm{L}$ (normal values <35), alanine aminotransferase (ALT): $235 \mathrm{IU} / \mathrm{L}$ (normal values <41), alkaline phosphatase (ALP): 350 IU/L (normal values $<129$ ), gamma-glutamyl transferase (GGT)ः 911 IU/L (normal values $<55$ ), total bilirubin: $1.55 \mathrm{mg} / \mathrm{dl}$ (normal values $<1.0$ ) and direct bilirubin: $0.82 \mathrm{mg} / \mathrm{dl}$ (normal values $<0.2)$ ]. Intra-extra hepatic biliary ducts were di-

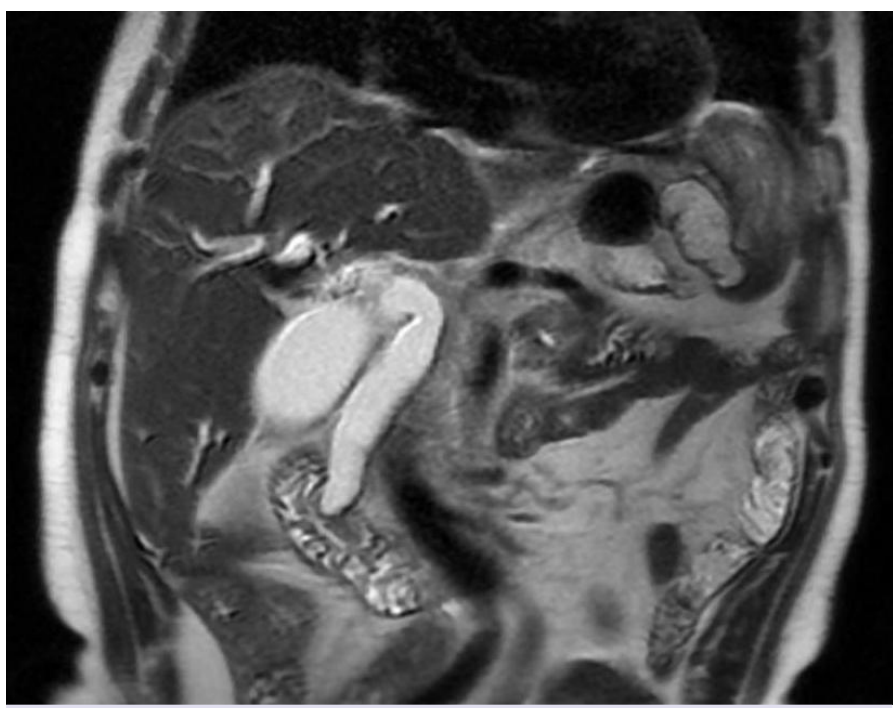

FIGURE 1. Blunt ending of common bile duct with $1 \mathrm{~cm}$ nodular lesion on periampullary region.

lated, and distal common bile duct had a blunt ending appearance on hepatobiliary ultrasonography (US), and $1 \mathrm{~cm}$ nodular lesion was observed on the periampullary region by magnetic resonance cholangiopancreatography (MRCP) evaluation (Fig. 1).
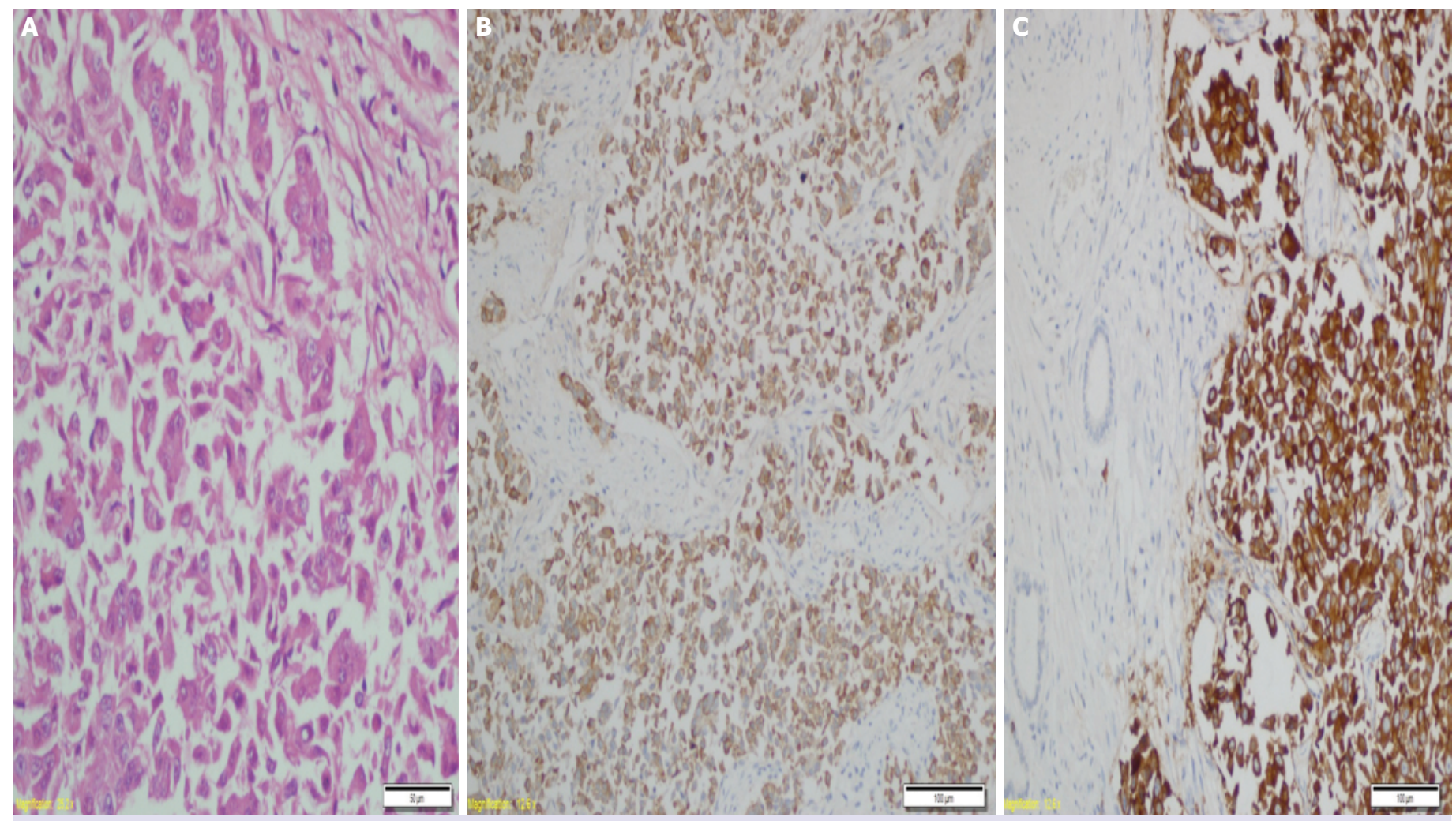

FIGURE 2. (A) Tumor cells with extensive eosinophilic cytoplasm, some with prominent nucleoli (H\&E, x400). (B, C) Immunohistochemical chromogranin A and synaptophysin expression in tumor cells (chromogranin A, x200; synaptophysin, x200). 
He was hospitalized to our General Surgery department for further assessment. On his endoscopic retrograde cholangiopancreatography (ERCP), there was a 'bulging' tumor appearance invading the orifice of the papilla. The preoperative biopsy of the suspected lesion was a 'neuroendocrine tumor' (NET).

Pylorus-preserving pancreaticoduodenectomy (PPPD) with regional lymph node dissection was performed. Pathologic diagnosis of the specimen was LCNEC (G3) (Fig. 2). Ki-67 labeling index was $80 \%$. Surgical margins were clear of tumor cells. Size of the tumor was $1.5 \mathrm{~cm}$, and a total of $17 \mathrm{lymph}$ nodes were dissected. None of the lymph nodes were positive.

The patient did not receive adjuvant therapy. Five months after the operation, he was screened by IV contrast-enhanced computerized tomography (CT) due to an increase in enzymes showing liver biochemistry. Multiple metastatic lesions located on both lobes of the liver, with the biggest one approaching nearly $4 \mathrm{~cm}$ in segment 8 was found on the CT scan. Biopsy of one of the lesions was reported as 'neurocarcinoma metastasis'. He was referred to oncology department to receive chemotherapy. However, the disease had an aggressive clinical course despite oncotherapy, and the patient had expired three months later. Patient's consent was obtained for this study.

\section{DISCUSSION}

Neuroendocrine tumors are uncommon neoplasms of the digestive tract. Even, ampulla of Vater NECs compromises less frequent percent in this group. Although advancement in technology eased the way for management using improvement in radiology (Multislice CT, magnetic resonance imaging (MRI), endoscopy and endoscopic US (EUS)), preoperative diagnosis of NECs is often challenging [5].

LCNECs are a rare and very aggressive subtype of NETs. Since they are not common, clinical features and treatment strategies are not established yet. According to some studies, tumor recurrence and poor survey rates are correlated with liver metastasis [6].

Previous studies claim that $50 \%$ of NEC of the ampulla of Vater bounder lymph node metastasis. Their recommendation is pancreaticoduodenectomy (PD) together with lymph node dissection for a better overall survey [7]. On the other hand, recent literature emphasizes more on the histopathologic features of the tumor (differentiation grade, small or large cell type) rather than 'TNM' or 'ENETS' (European Neuroendocrine Tumor Society) staging systems in predicting the overall course and treatment strategy [8].

We performed PD with lymph node dissection for our case. According to the WHO classification system, it was a G3 (Grade 3) tumor having an $80 \%$ Ki-67 labeling index. Oncology preferred close follow-up with a conservative approach instead of giving oncotherapy. In a study presented by Naoya Imamura et al. [8], adjuvant chemotherapy after radical resection performed for LCNECs was found with better the overall survey without any relapses in the long term. In "The NANETS Consensus Guidelines for the Diagnosis and Management of Poorly Differentiated (High-Grade) Extrapulmonary Neuroendocrine Carcinomas' which was conducted by Strosberg et al. [9], adjuvant chemotherapy (4-6 cycles of cisplatin or carboplatin and etoposide) is recommended regarding the post-operative treatment of poorly differentiated NECs. Given the tumor characteristics of our case, it could be a better choice to give adjuvant therapy to prevent distant organ metastasis.

\section{Conclusion}

We presented our clinical experience of LCNEC of ampulla of the Vater. These uncommon tumors may have a very aggressive clinical behaviour despite small tumor size and/or lymph node negativity. Especially for tumors equal or larger than $1 \mathrm{~cm}$ and having a high percent $\mathrm{Ki}$ 67 labeling index, radical surgery with adjuvant therapy may increase the overall survey.

Informed Consent: Written informed consent was obtained from the patient for the publication of the case report and the accompanying images.

Conflict of Interest: No conflict of interest was declared by the authors.

Financial Disclosure: The authors declared that this study has received no financial support.

Authorship Contributions: Concept - RES, FB; Design - RES, RBG; Supervision - GB, OA; Funding - RBG; Materials - RBG, TTE; Data collection and/or processing - FB, TTE; Analysis and/or interpretation - RES, FB; Literature review - GB, OA; Writing - RES, TTE; Critical review - GB, OA.

\section{REFERENCES}

1. Albores-Saavedra J, Hart A, Chablé-Montero F, Henson DE. Carcinoids and high-grade neuroendocrine carcinomas of the ampulla of vater: a comparative analysis of 139 cases from the surveillance, epi- 
demiology, and end results program-a population based study. Arch Pathol Lab Med 2010;134:1692-6.

2. Bossman FT, Carneiro F, Hruban RH, Treise ND. WHO Classification of Tumors of the Digestive System. 4th ed. Lyon: IARC Press; 2010 .

3. Beggs RE, Kelly ME, Eltayeb O, Crotty P, McDermott R, Ridgway PF. Large cell neuroendocrine carcinoma of the ampulla of Vater. JOP 2012;13:470-5.

4. Oronsky B, Ma PC, Morgensztern D, Carter CA. Nothing But NET: A Review of Neuroendocrine Tumors and Carcinomas. Neoplasia 2017;19:991-1002. [CrossRef]

5. Liu SH, Tsay SH. Coexistence of large cell neuroendocrine carcinoma and adenocarcinoma of the ampulla of vater. J Chin Med Assoc 2008;71:536-40. [CrossRef]

6. Cokmert S, Demir L, Akder Sari A, Kucukzeybek Y, Can A, Akyol
M, et al. Synchronous Appearance of a High-Grade Neuroendocrine Carcinoma of the Ampulla Vater and Sigmoid Colon Adenocarcinoma. Case Reports in Oncological Medicine 2013;1-4. [CrossRef]

7. Salmi S, Ezzedine S, Vitton V, Ménard C, Gonzales JM, Desjeux A, et al. Can papillary carcinomas be treated by endoscopic ampullectomy? Surg Endosc 2012;26:920-5. [CrossRef]

8. Imamura N, Nanashima A, Hiyoshi M, Fujii Y. Report of two cases of large cell neuroendocrine carcinoma of duodenal ampulla with contrasting outcomes following pancreaticoduodenectomy according to the use of adjuvant chemotherapy. Int J Surg Case Rep 2017;31:132-8.

9. Strosberg JR, Coppola D, Klimstra DS, Phan AT, Kulke MH, Wiseman GA, et al; North American Neuroendocrine Tumor Society (NANETS). The NANETS consensus guidelines for the diagnosis and management of poorly differentiated (high-grade) extrapulmonary neuroendocrine carcinomas. Pancreas 2010;39:799-800. [CrossRef] 